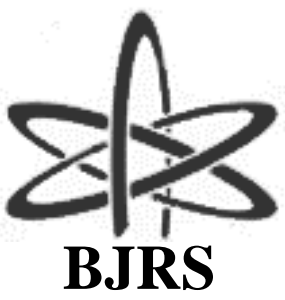

BRAZILIAN JOURNAL
OF
RADIATION SCIENCES
08-03B (2021) 01-16

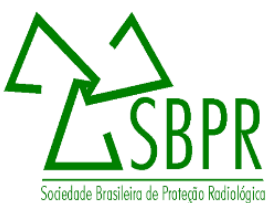

\title{
Calculation of scale thickness in oil pipelines using transmission gamma
}

\author{
Tâmara Porfíro Teixeira, César Marques Salgado \\ Instituto de Engenharia Nuclear \\ tamarateixeira.eng@gmail.com
}

\begin{abstract}
Scale can be defined as chemical compounds inorganic, initially insoluble, and which precipitate accumulating in the internal wall of pipes, surface equipment and/or parts of components involved in the production and transport of oil. These compounds, when precipitating, cause problems in the oil industry and consequently result in losses in the optimization of the extraction process. Although the importance and impact of the precipitation of these compounds in the technological and economic scope, there is still the difficulty in determining methods that enable the identification and quantification of the scale at an initial stage. The use of the gamma transmission technique may provide support for a better understanding of the deposition of these compounds, making it a suitable tool for the noninvasive determination of their deposition in oil transport pipelines. The geometry used for the scale detection include a $280 \mathrm{~mm}$ diameter iron pipe containing barium sulfate $\left(\mathrm{BaSO}_{4}\right)$ ranging from 5 to $60 \mathrm{~mm}$, gamma radiation source with divergent beam and as $\mathrm{NaI}(\mathrm{Tl}) 2$ 2"x2" scintillation detector. The opening size of the collimated beam was evaluated ( 2 to $7 \mathrm{~mm}$ ) to also quantify the associated error in calculating the scale. The study was realized with computer simulation, using the MCNP-X code and validated by means of analytical equations that indicate the possibility of using this study for this purpose.
\end{abstract}

Keywords: transmission gamma, scale, MCNP-X code, oil pipelines.

ISSN: 2319-0612

Accepted: 2021-02-09 


\section{INTRODUCTION}

During the process of formation of oil and gas, already allocated in reservoir rocks, there is also a production of water called formation water. This presents characteristics inherent to the rock to which it is located, and its quantity will depend on the characteristics of the natural or artificial mechanisms of production and the composition characteristics of the reservoir rock itself. The water produced from the reservoir rock is identified by its salinity and chemical composition (Bessera, 2012). To maintain the pressure conditions in the reservoir rock, a water injection operation can be carried out in the lower layers of the rock, favoring the migration and collection of the natural material of interest to the wells.

Oil extraction is accompanied by water and sediment, which mixed with the oil and together with changes in pressure, temperature and fluid flow can cause these elements to precipitate forming deposits of on the walls of the pipes. Due to the chemical affinity of the elements soluble in the sea water and the formation water, chemical reactions may occur that will favor the formation of inorganic deposit, the scales.

Scale may cause: reduction of internal pipe diameters due to accumulation of deposited products, drilling at pipe points and equipment due to corrosion promoting agents, increased energy consumption due to reduced equipment efficiency and shortened life equipment and installation (Fiorentin, 2004).

Scales of barium, strontium and calcium, for example, are usually formed by the mixture of formation water and injection water. The high concentration of sulfate anions presents in the injection water when interacting with high concentrations of divalent cations $\left(\mathrm{Ba}^{2+} \mathrm{Sr}^{2+} \mathrm{e}\right.$ $\mathrm{Ca}^{2+}$ ) present in the formation water under favorable thermodynamic conditions may result in the formation of sulfate salt precipitates.

Over time, these salts gradually deposit on the walls of the pipes and equipment used in the extraction and transport of oil/gas, contributing to reduce the internal diameter of the pipes, contributing to reduce the internal diameter of the pipes, and may even obstruct passages and damage equipment, necessitating periodic maintenance actions, such as cleaning or even tube 
replacement (Martin, et al., 1997). Thus, scale causes economic losses due to the impact on increased operating costs and equipment performance in offshore operations (Allen, et al., 1982).

Scale depositions limit and sometimes block the production of oil and gas through the obstruction of the oil formation matrix. It can also damage production lines and equipment and interfere with fluid flow. The direct consequence of this is the failure of production equipment, emergency shutdowns, increased maintenance cost (predictive and corrective) and general decrease of production efficiency (Oliveira, 2009). In this sense, there is a need to deepen the studies as a way of identifying and quantifying the fouling to carry out the evaluations of corrective and preventive measures.

Nuclear techniques, which are non-invasive, have been a potential solution for preventive control and monitoring of Scale evolution, mainly used to monitor and quantify fouling in the offshore environment.

From the economic point of view, the non-destructive testing procedures seem to have a promise in the evaluation of deposits (Marinho, et al., 2008). Once a system is in place and in perfect working order, it is often not wise to interrupt it to conduct a study. In practice, there are relevant difficulties to obtain results through destructive examinations. In fact, the advantage is that non-destructive testing can often be performed at convenient times and not necessarily result in interruption of operations.

The gamma-ray densitometry technique, one of the non-destructive test methods, has been applied and obtained satisfactory results in many areas, such as petrochemical, oil industry and mining (Salgado, et al., 2013). It has been used for flow measurement studies (Mi, et.al., 1998; Salgado, et al., 2009); for density prediction (Achmad, 2004), for the study of thickness measurements (Berman, 2009) and oil transport monitoring applications (Khorsandi, 2011); for the detection of scale and corrosion in pipes used for oil extraction (Monno, 1985; Mcconn, 2011).

This technique makes use of radioactive sources of gamma rays and through them it is possible to obtain measurements without, however, modifying the operating conditions of the system under study, allowing to follow the whole process of monitoring. Nuclear techniques based on gamma-ray absorption methods can provide reliable measures of thickness fluctuation, 
for example, by improving accuracy and reducing costs. However, in this type of measures difficulties are encountered, such as the presence of water, gas or oil due to differences in density, which interferes with the accuracy in estimating the scale thickness. There is, therefore, a need to evaluate the behavior of the radiation beam in the most realistic scenario possible, that is, considering the influence of the fluids in a tube-fouling-fluids system.

Analysis by transmission measurements can be achieved by comparing the signals recorded by the detector with a content of a density calibration table or by using analytical equations. In any case, the calibration table can be influenced by important parameters that depend on the measurement conditions, such as: pipe diameter, pipe wall thickness, temperature and pressure, and even errors caused by the calibration procedure itself (Maucec and Denijs, 2009). It is necessary to investigate the impact of these parameters on the density measurement. In both procedures, simplifications, based on experimental data, are often performed on the analytical model for an approximate solution, however this may lead to large errors due to changes in flow regime occurring in time and space. In addition, the solution through analytical equations is specific to a given flow regime and measurement geometry, and obviously there can be no significant changes in the system for the solution to have any meaning.

\section{MATERIALS AND METHODS}

The present section is related to the study of the gamma transmission method using the Monte Carlo N-particle (MCNP-X) code and the method used to predict the thickness of concentric inorganic scale of barium sulphate in oil pipes.

\subsection{Representative materials and geometry}

Initially, a study of representative materials for pipe and scale was carried out, in order to optimize the obtaining of the data required for scale calculation through simulated models. In order to obtain a model with a simplified and representative geometry of the pipe-scale-fluid system necessary for scale calculation, preliminary gamma transmission studies were carried out using the following steps:

1. Evaluation of the influence of the chemical composition of the pipes; 
2. Evaluation of the influence of the chemical composition of scales;

3. Obtaining the coefficients of linear attenuation of the pipe, scale and fluid used;

4. Definition of the most appropriate collimation aperture;

After defining all the geometry of the chemical composition of the materials that make up the model, it will be used for all other simulations, where increments of scale thickness and variation of positions of the source-detector system will be performed in order to validate the adopted model.

\subsubsection{Evaluation of the influence of the chemical composition of the pipes}

The pipes used to transport oil, the walls have direct contact with the fluids being transported, being subject to corrosion. For this reason, galvanized steel (A1SO16, A1S1304L, A1316L, etc.) and stainless steel are used in its manufacture. However, the ability to represent a pipeline made up essentially of iron was evaluated in comparison with other metal alloys found in pipelines used in the petrochemical industry. For this, simulations were carried out with the pipe essentially formed by iron and other simulations with pipes formed by metallic mixtures, namely, AlS1304, AlS1307 and AlS1316 (Chrome-Nickel Molybdenum Steels), as shown in Table 1.

Table 1- Chemical composition of AlSl304, AlSl307 and AlSl316 steels (William et al., 2006)

\begin{tabular}{cccc}
\hline Elemento & AlSI 304 & AlSI 307 & AlSI 316 \\
\hline $\mathrm{Fe}$ & 0,68827 & 0,65075 & 0,67259 \\
$\mathrm{Cr}$ & 0,20209 & 0,18140 & 0,18982 \\
$\mathrm{Mo}$ & - & 0,01446 & - \\
$\mathrm{Mn}$ & 0,02013 & 0,02020 & 0,01996 \\
$\mathrm{Ni}$ & 0,08951 & 0,11344 & 0,09810 \\
$\mathrm{Si}$ & - & 0,01976 & 0,01952 \\
\hline
\end{tabular}

The geometry developed to carry out the study of gamma transmission and determination of the representative composition used a monoenergetic punctiform source of cesium 137 with a pencil beam positioned $180^{\circ}$ from a 2 "x2 " scintillating $\mathrm{NaI}(\mathrm{Tl})$ detector. A pipe with an 
initial internal diameter of $27.5 \mathrm{~cm}$ and a length of $20 \mathrm{~cm}$; thickness ranging from 0.5 to $4 \mathrm{~cm}$ in $0.5 \mathrm{~cm}$ steps; source-pipe and pipe-detector distances of both $1 \mathrm{~cm}$ were evaluated in this study.

\subsubsection{Evaluation of the influence of the chemical composition of the scales}

Scales are formed by salts and can contain more than one compound in their composition. However, according to chemical analyzes, approximately $61 \%$ of the chemical composition of the scale is formed by barium sulfate. To evaluate the representativeness of $\mathrm{BaSO} 4$ as the only inorganic salt that forms scale, two simulations were carried out: one with barium sulfate ( $\rho=$ $4.5{\mathrm{~g} . \mathrm{cm}^{-3}}^{-}$and the other with about $80 \%$ by weight of barium sulfate containing about $20 \%$ mass of $\mathrm{SrSO}_{4}, \mathrm{Fe}_{2} \mathrm{O}_{3}, \mathrm{CaCO}_{3}, \mathrm{SiO}_{2}$ and $\mathrm{Al}_{2}\left(\mathrm{SiO}_{4}\right)_{3}$, see Table 2.

Table 2 - Chemical composition of $\mathrm{BaSO}_{4}$ e $\mathrm{BaSO}_{4} *$ with $\mathrm{SrSO}_{4}, \mathrm{Fe}_{2} \mathrm{O}_{3}, \mathrm{CaCO}_{3}, \mathrm{SiO}_{2}$ and

\begin{tabular}{ccc}
\multicolumn{3}{c}{$\mathrm{Al}_{2}\left(\mathrm{SiO}_{4}\right)_{3}}$. \\
\hline Element & $\mathbf{B a S O}_{4}$ & $\mathbf{B a S O}_{4}{ }^{*}$ \\
\hline $\mathrm{Al}$ & - & 0,03 \\
$\mathrm{Ba}$ & 0,589 & 0,368 \\
$\mathrm{C}$ & - & 0,013 \\
$\mathrm{Ca}$ & - & 0,045 \\
$\mathrm{Fe}$ & - & 0,017 \\
$\mathrm{O}$ & 0,274 & 0,331 \\
$\mathrm{~S}$ & 0,137 & 0,114 \\
$\mathrm{Si}$ & - & 0,034 \\
$\mathrm{Sr}$ & - & 0,075 \\
\hline
\end{tabular}

The study consisted of comparing the interaction of radiation between scales consisting only of barium sulfate and barium sulfate and other compounds (Cruz, 2002; Godoy and Cruz, 2003) and the geometry used was the same as in item 2.1.1.

\subsubsection{Obtaining the coefficients of linear attenuation of the pipe, scale and fluid}

The attenuation coefficient values for all materials that make up the measurement system were selected and studied. For this, information such as density $\left(\mathrm{g} . \mathrm{cm}^{-3}\right)$ and mass 
fractions of iron pipe, barium sulphate scale and oill were required as input data for the MCNP-X code for calculating the attenuation coefficient (Willian et al., 2009). Table 3 presents these coefficient values and their comparison with theoretical data contained in the National Institute of Standards and Technology (NIST, 2010). These data were useful for calculating the thickness of the scale.

Table 3: Linear Attenuation Coefficients for pipe, scale and oil.

\begin{tabular}{|c|c|c|c|}
\hline Data & Pipe & Scale & Oil \\
\hline Density $\left(\mathrm{g} . \mathrm{cm}^{-3}\right)$ & 8 & 4.5 & 0.973 \\
\hline $\begin{array}{l}\text { Linear attenuation coeficient } \\
\text { (MCNPX) }\end{array}$ & $5.78 \mathrm{E}-01$ & $1.90 \mathrm{E}-01$ & $7.75 \mathrm{E}-02$ \\
\hline $\begin{array}{l}\text { Linear attenuation coeficient } \\
\text { (NIST) }\end{array}$ & $5.80 \mathrm{E}-01$ & $1.96 \mathrm{E}-01$ & $8.38 \mathrm{E}-02$ \\
\hline Relative error $(\%)$ & -0.29 & -3.12 & -7.51 \\
\hline
\end{tabular}

\subsubsection{Definition of the most appropriate collimation aperture}

To optimize the activity of the radioactive source of ${ }^{137} \mathrm{Cs}$, a study of the effect of collimation was carried out, in which the influence of the collimation aperture in the calculation of the scale was evaluated. This collimation influence consisted in varying the divergence of the radiation beam using a pencil-beam $\left(0^{\circ}\right), 2 \mathrm{~mm}\left(5.73^{\circ}\right), 4.5 \mathrm{~mm}\left(12.64^{\circ}\right)$ and $7 \mathrm{~mm}\left(21,37^{\circ}\right)$ and use analytical equations to determine the thickness of the scales under all these divergences. The thicknesses were previously defined as $0.5 \mathrm{~cm}$ for all cases and studied at six source-detector displacement points, namely, from $3 \mathrm{~cm}$ to $6.5 \mathrm{~cm}$, with $0.5 \mathrm{~cm}$ steps, aiming at profiling the pipe.

The divergence of the source was mathematically developed with the desired emission, without the use of a real collimator, making use of commands available in the MCNP-X code, where the source adopts the conical shape with normalization of the $4 \pi$ emission. The most appropriate value for collimations will be used in the validation phase for other scales thicknesses, considering a lower relative error. 


\subsection{Simulation geometry for scales thicknesses}

The detection geometry consists of a $2 \times 2 " \mathrm{NaI}(\mathrm{Tl})$ scintillation detector, positioned at $180^{\circ}$ from a point source of ${ }^{137} \mathrm{Cs}(662 \mathrm{keV})$ gamma rays. Considering that the analytical equations used for calculating thickness are valid for a pencil-beam beam, a study of source divergence was carried out with the objective of optimizing the source activity and evaluating the associated errors in the scale calculus. The divergence established initially for the source was $5.73^{\circ}$, which corresponds to a collimator with a $2 \mathrm{~mm}$ aperture in the geometry established in this work. To evaluate the influence of the divergence of the source, the opening of the collimator was varied from $2 \mathrm{~mm} ; 4.5 \mathrm{~mm}$ and $7 \mathrm{~mm}$. The most appropriate value for the collimator, after the simulations, will be used in the scale calculation.

A source, also punctual, pencil-beam was also used for comparative purposes and all these tests were performed through the MCNP-X code. It should be noted that the source divergence was mathematically developed with the desired emission, without the use of an actual collimator, using the commands provided in the MCNP-X Code. The pipe used is essentially made of iron and has a thickness of $5 \mathrm{~mm}$ and $280 \mathrm{~mm}$ of external diameter. The fluid used was crude oil. To obtain the scale thickness, its value from 0,5 to $6 \mathrm{~cm}$ containing concentric scales and formed by only $\mathrm{BaSO}_{4}$ was varied, as shown in Fig.1.

Figure 1: Simulation System

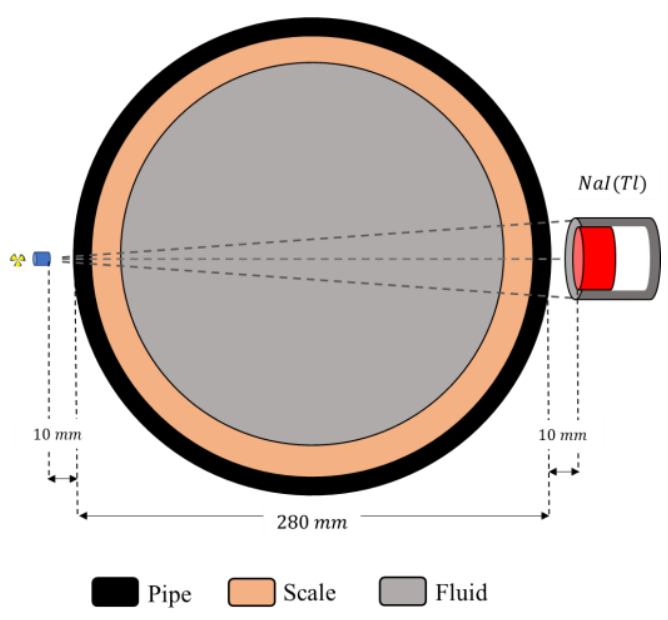


The simulation responses were obtained using the output commands available in the code, to study the influence of the collimator using the command (F1, tally card), while the command (F8, tally card) was used for the study of the scale value. These commands display a relative error due to counts in each spectrum energy range. The number of histories (NPS) used was determined to obtain acceptable statistics, with relative error values lower than $5 \%$ for 662 keV energy, according to the MCNP-X manual (Pelowitz, 2005).

\subsection{Calculation of the scale thickness}

Analytical equations were obtained for calculating the scale thickness. The path traveled by the radiation in the fouling is provided by Eq. 1 and Eq. 2, to obtain the fouling thickness, Eq. 3. The method used in this work also considers possible misalignment source-detector.

$$
\begin{gathered}
\mathrm{W}_{\text {inc }}=\frac{\ln \mathrm{K}+\mu \mathrm{D} * \mathrm{wD}+\mu \mathrm{F} * \mathrm{wI}}{-\mu \mathrm{INC}+\mu \mathrm{F}} \\
\mathrm{W}_{\mathrm{I}}=\mathrm{wINC}+\mathrm{wF} \\
\mathrm{X}_{\mathrm{AB}}=\sqrt{(\mathrm{Xa}-\mathrm{Xb})^{2}}+\sqrt{(\mathrm{Ya}-\mathrm{Yb})^{2}}
\end{gathered}
$$

Equation 1

Equation 2

Equation 3

Where:

$k: k=I / I_{0}$;

$\mu_{\mathrm{i}}:$ transmission coefficient for the pipe, scale and fluid $\left(\mathrm{cm}^{-1}\right)$;

$W_{i}:$ radiation path to the pipe, scale and fluid $(\mathrm{cm})$;

$X_{A B}$ : scale thickness $(\mathrm{cm})$;

$X_{a}, X_{b}, Y_{a}$ and $Y_{b}$ : coordinates of the line segment $A B$ that refers to the value of the thickness.

The simulations were performed using the MCNP-X code to obtain the gamma transmission in 8 different positions of the pipe, from $3 \mathrm{~cm}$ to $6.5 \mathrm{~cm}$ in steps of $0.5 \mathrm{~cm}$. These values are necessary to calculate the scale thickness, according to Fig. 2. 


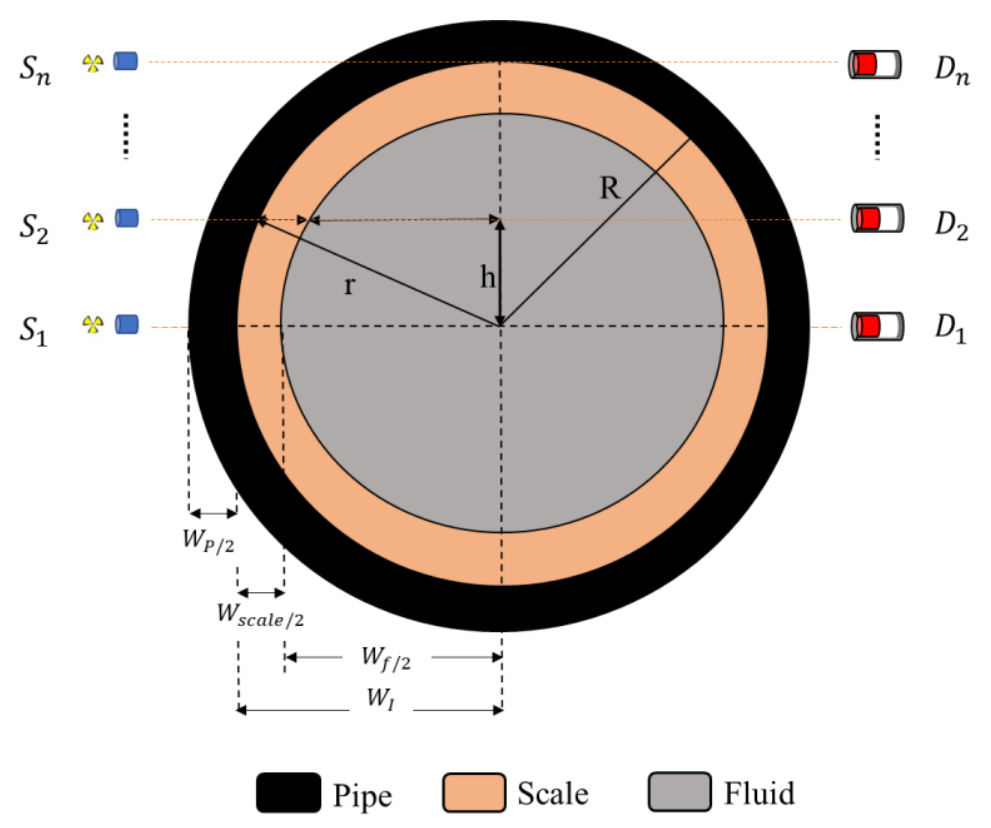

Figure 2: Representation of the trigonometric relationships of the pipe, (oil) and scale.

Simulations were obtained with the MCNP-X code, using the tally card F8 for pulse height distribution estimative, and only the corresponding region of the photoelectric absorption was used. To ensure that the relative error associated with the counts of each detector was below $5 \%$ for all the cases, the calculation accounted to 1E7 NPS.

\section{RESULTS AND DISCUTIONS}

This section is presented the steps to calculate the scale of barium sulfate thickness with analytical equations.

\subsection{Scale thickness by analytical equations}

Fig. 3 shows the simulation response for the pipelines considering the steels mentioned in 2.1.1.

From the relative error (\%) data, it can be seen that the values show deviations below $1 \%$, so there is no significant difference between steels and iron. The analyzed steels have about $70 \%$ iron in their composition, and the other chemical elements analyzed have atomic numbers close 
together and relatively low mass fraction in the metallic alloy, having little influence on the linear attenuation coefficient values, explaining relatively low errors.

Figure 3 - Relative errors of AlSl304, AlSl307, AlSl316 in relation to Fe.

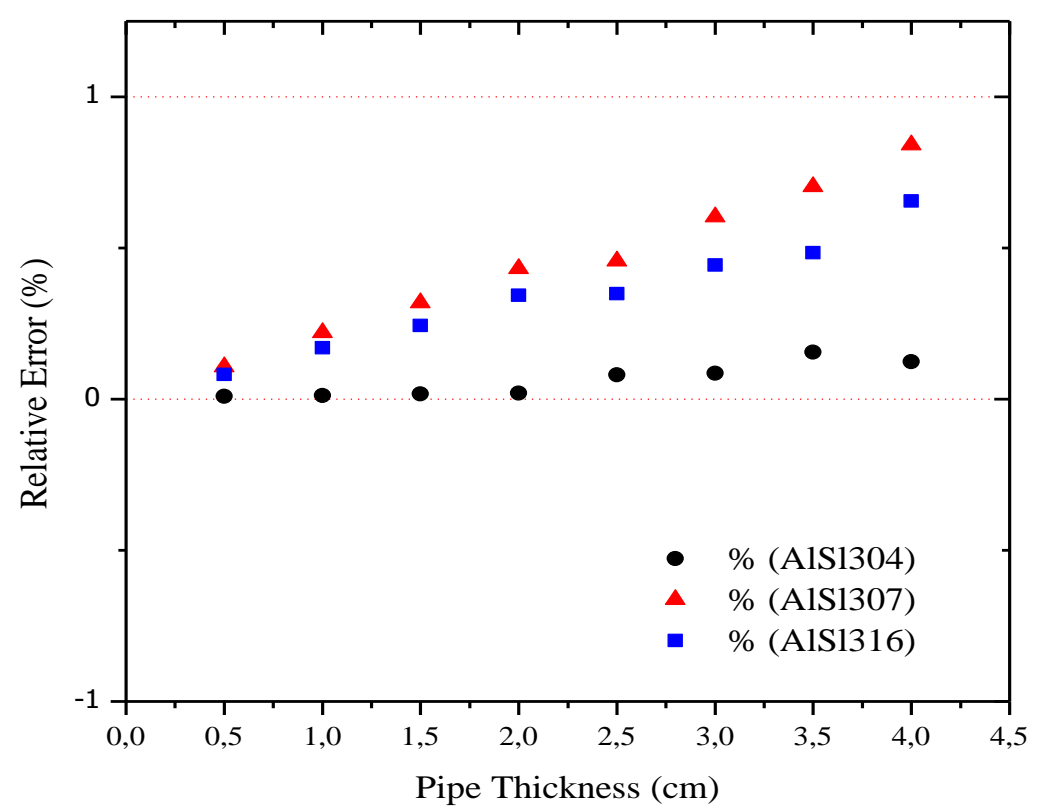

Therefore, the use of iron as the only constituent component of the pipe will not have a significant influence on the transmission and, consequently, on the calculation of the incrustation thickness.

Fig. 4 shows the relative percentage error regarding the gamma transmissions obtained by the simulations for the increments of barium sulfate $\left(\mathrm{BaSO}_{4}\right)$ and barium sulfate with the other $\mathrm{BaSO}_{4} *$ salts $\left(\mathrm{BaSO}_{4}, \mathrm{SrSO}_{4}, \mathrm{CaCO}_{3}, \mathrm{Fe}_{2} \mathrm{O}_{3}, \mathrm{SiO}_{2}\right.$ and $\left.\mathrm{Al}\left(\mathrm{SiO}_{4}\right)_{3}\right)$ in its composition, as mentioned in section 2.1.2. 
Figure 4 - Relative errors of $\mathrm{BaSO}_{4}$ * in relation to $\mathrm{BaSO}_{4}$.

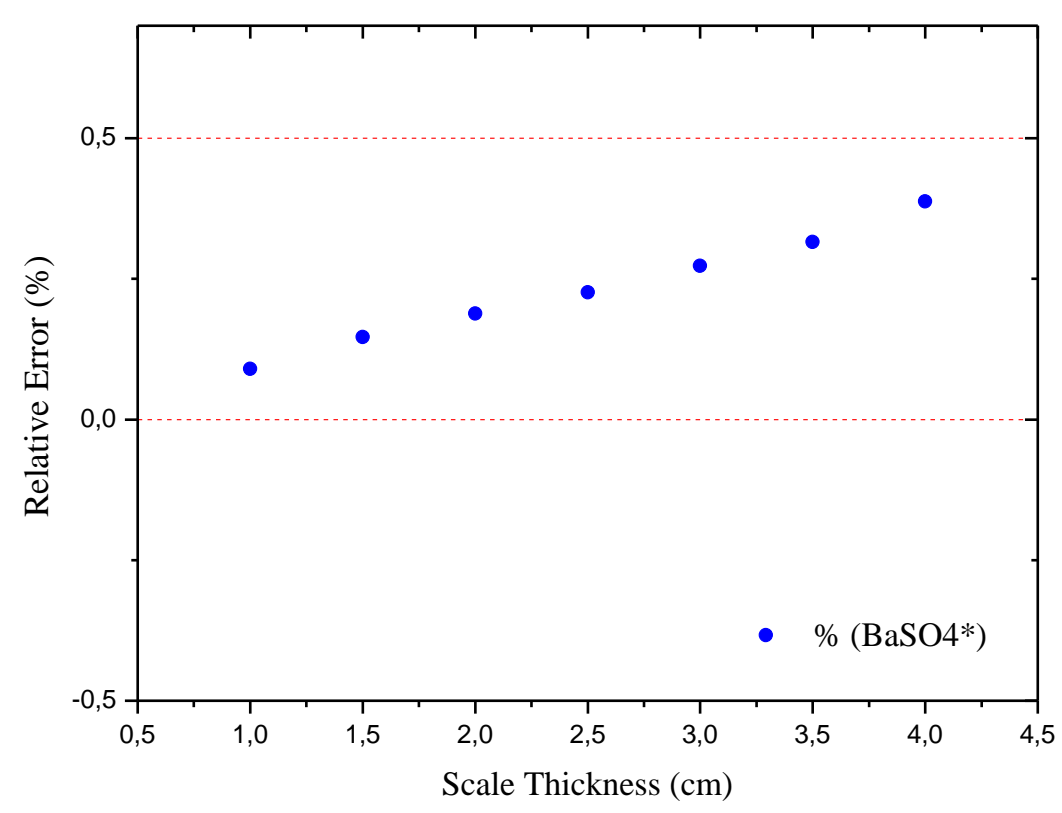

As can be seen, all the relative error values showed deviations below $0.5 \%$. The other salts that make up the mixture of barium sulfate with other inorganic salts (BaSO4*) contain in their chemical composition about $82 \%$ of the total mass fraction of barium, sulfur and oxygen, thus justifying the values of relatively low errors. The chemical elements that make up both models have atomic numbers close to each other, implying proximity in the linear attenuation coefficient values, also justifying deviations less than $0.5 \%$ obtained in this study. Therefore, the use of barium sulfate as the sole constituent of the scale in all models will not significantly influence the calculation of the scale thickness.

In Fig. 5 is presented the thickness of the scale with a pencil-beam source and a collimation aperture for crude oil, also varying the detection height and an initial nominal scale of 0.5 $\mathrm{cm}$. By means of this study, the collimation aperture was defined with the lowest percentage relative error and adopted as the most adequate for the calculation of other scale thicknesses, with thicknesses varying from $2 \mathrm{~cm}$ to $6 \mathrm{~cm}$.

The thickness of the scale was obtained (Fig. 5), with your respective percentage relative errors. It is possible to notice that the geometry using pencil beam source and $2 \mathrm{~mm}$ presented the values closest to the theoretical value of $0.5 \mathrm{~cm}$. In the other two cases, with divergence of $4.5 \mathrm{~mm}$ and $7 \mathrm{~mm}$, relative errors are relatively larger, maximum of $4.06 \%$. This increase in the 
relative error in the last cases, where the beam angulation was extrapolated, demonstrates the importance in defining the geometry and the correct adjustment of the divergence.

Figure 5: Scale thickness for collimation openings.

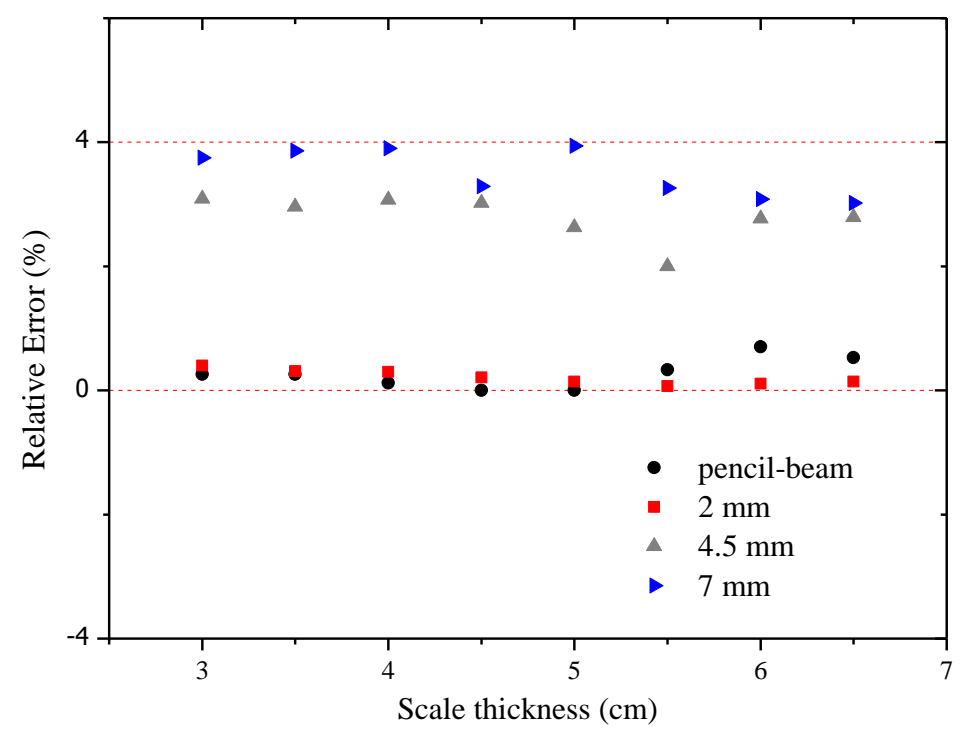

In a second moment, the studies were carried out with variation of nominal scale of 2 to $6 \mathrm{~cm}$, maintaining the divergence adjusted of $2 \mathrm{~mm}$ and the source pencil beam for comparative effect, since these data were those that presented smaller relative error. In Table 4 the scale thickness data are presented and the percentage relative errors theoretical, respectively.

Table 4: Scale thicknesses obtained by the gamma transmission technique for nominal scale of $2 \mathrm{~cm}, 4 \mathrm{~cm}$ and $6 \mathrm{~cm}$.

\begin{tabular}{|c|c|c|c|c|c|c|}
\hline \multirow[b]{2}{*}{$\begin{array}{l}\text { HEIGHT } \\
(\mathbf{c m})\end{array}$} & \multicolumn{2}{|c|}{$2 \mathrm{~cm}$} & \multicolumn{2}{|c|}{$4 \mathrm{~cm}$} & \multicolumn{2}{|c|}{$6 \mathrm{~cm}$} \\
\hline & $\begin{array}{l}\text { SCALE } \\
\text { TICKNESS } \\
\text { (cm) }\end{array}$ & $\begin{array}{l}\text { RELATIVE } \\
\text { ERROR (\%) }\end{array}$ & $\begin{array}{c}\text { SCALE } \\
\text { TICKNESS } \\
\text { (cm) }\end{array}$ & $\begin{array}{l}\text { RELATIVE } \\
\text { ERROR (\%) }\end{array}$ & $\begin{array}{c}\text { SCALE } \\
\text { TICKNESS } \\
(\mathbf{c m})\end{array}$ & $\begin{array}{l}\text { RELATIVE } \\
\text { ERROR (\%) }\end{array}$ \\
\hline 3 & 1,99 & $-0,71$ & 3,98 & $-0,56$ & 5,96 & $-0,65$ \\
\hline 3,5 & 1,99 & $-0,73$ & 3,98 & $-0,60$ & 5,97 & $-0,55$ \\
\hline 4 & 1,99 & $-0,64$ & 3,98 & $-0,51$ & 5,97 & $-0,57$ \\
\hline 4,5 & 1,99 & $-0,56$ & 3,99 & $-0,36$ & 5,97 & $-0,48$ \\
\hline 5 & 1,99 & $-0,57$ & 3,99 & $-0,24$ & 5,98 & $-0,26$ \\
\hline 5,5 & 1,99 & $-0,44$ & 4,00 & 0,10 & 6,01 & 0,09 \\
\hline 6 & 1,99 & $-0,47$ & 4,00 & 0,06 & 6,04 & 0,70 \\
\hline 6,5 & 1,99 & $-0,49$ & 4,00 & 0,06 & 6,09 & 1,46 \\
\hline
\end{tabular}


In all cases, with thicknesses of 0.5 to $6 \mathrm{~cm}$, the fouling thicknesses were obtained with good detection sensitivity. These cases presented relative errors lower than $1.46 \%$, in the worst case.

\section{CONCLUSIONS}

This work evaluated a geometry of detection of a gamma transmission system, as well as studying an influence of the opening of the divergence of a point source, a position of the detection system, of source-detector form, an influence of the composition of the damages and scales, aiming a repetition of a geometry that evaluated the impact of these parameters for quantification of barium sulphate scale $\left(\mathrm{BaSO}_{4}\right)$ in oil pipes. The calculation of the scale thicknesses was obtained by means of analytical equations and computational simulation (MCNP-X). The results of the calculation of the fouling thickness presented relative errors lower than $1.46 \%$, demonstrating the good agreement between the initially theoretical values and those obtained by the simulation. It is worth noting that the proposed method also predicts a possible misalignment of the sourcedetector system, making use of analytical equations to overcome this problem, indicating that this methodology can be used in a satisfactory way to predict the thickness of deposits in oil pipes.

\section{ACKNOWLEDGMENTS}

The authors gratefully acknowledge the financial support from the Comissão Nacional de Energia Nuclear (CNEN) of Brazil. Thanks, are also to Instituto de Engenharia Nuclear (IEN) of Brazil by academic support.

\section{REFERENCES}

ALLEN, T.O. AND ROBERTS, A.P., Production Operations, $2^{\text {rd }}$ ed., Tulsa, OK, 1982. p. 1119.

ACHMAD B. E HUSSEIN E.M.A., An X-ray Compton scatter method for density measurement at a point within an object, Applied Radiation and Isotopes, 2004. p. 805-814. 
BESERRA, M. T. F. Evaluation of the scale thickness in oil extraction ducts, M.Sc., Institute of Radioprotection and Dosimetry - National Commission for Nuclear Energy, IRD-RJ, Rio de Janeiro, RJ, Brazil, 2012.

CRUZ, R. P, Estudo da Composição Química de Borras e Incrustações oriundas das atividades de produção de petróleo e sua correlação com a Radioatividade Natural - Estudo de Caso: Bacia de Campos-Brasil. M.Sc, PUC/RJ, Rio de Janeiro, RJ, Brasil, 2002.

ERMAN, A.I., HARRIS, J.N., Precision Measurement of Uniformity, of Materials by Gamma Ray Transmission, Review Scientific Instruments, 1954.

FIORENTIN, L. D. Study of Mathematical Models for Predicting Coke Intake in Pipes Application to the Residual Diesel Distributor of a Vacuum Distillation Tower, M.Sc., CEFET-PR, Paraná, PR, Brazil, 2004.

KHORSANDI M. E FEGHHI S.A.H., Design and construction of a prototype gamma-ray densitometer for petroleum products monitoring applications. Measurement, 44, 2011. p. $1512-1515$.

LANL, A General Monte Carlo N-Particle Transport Code, $5^{\text {rd }}$, Volume III: Developer's Guide. Los Alamos, University of California for the U.S.A, 2003.

MARINHO, A.C, COSTA, D.R., SANTOS, E., COSTA, K.A., OLIVEIRA, D.; LOPES, R.T., Monitoring and Quantification of Fouling by Radiographic Methods. In: National Congress of Non-Destructive Testing, São Paulo, SP, Brazil, 2008.

MARTIN A., MEAD S., WADE B. O., Materials Containing Natural Radionuclides in Enhanced Concentrations, European Commission Report EUR 17625, 1997.

MAUCEC, M. AND DENIJS, I., Development and calibration of a gamma-ray density meter for sediment-like materials. Appl. Radiat. Isot., 67, 2009. p. 1829-1836.

MCCONN JR., RJ, GESH, C.J., PAGH, R.T., RUCKER, R.A., WILLIAMS, R.G., Compendium of Material Composition Data for Radiation Transport Modeling, Radiation portal monitor project, Pacific Northwest, National Laboratory. PIET-43741-TM-963 PNNL-15870 Rev. 1, 2011.

MI, Y., ISHII, M. E TSOUKALAS, L.H., Vertical two-phase flow identification using advanced instrumentation and neural networks. Nuclear Engineering and Design, 184, pp.409-420, 1998. 
MONNO, A., Tube Wall Thickness, GB Patent Document 2146115/A/, GB Patent Aplication 8323913, Int. Cl. G01B 15/02, 9 p., April, 1985.

NIST, Nacional Institute of Standards and Technology. Available online: http://physics.nist.gov/xaamdi, Last accessed: 04 jul. 2017.

OLIVEIRA, D., Development of a System Based on Transmission of Gamma Radiation for Detection of Scales in Pipelines used for oil extraction, International Nuclear Atlantic Conference - INAC, Rio de Janeiro, RJ, Brazil, 2009.

SALGADO C.M., BRANDÃO L.E.B., NASCIMENTO C.M.N.A., SCHIRRU R., RAMOS R. E SILVA A.X., Prediction of volume fractions in three-phase flows using nuclear technique and artificial neural network, Applied Radiation and Isotopes, 67, 2009. p. 18121818.

SALGADO C. S., BRANDÃO L. E. B., NUNES R. C., NASCIMENTO A. C. H, SALGADO W. L., Study of Solid-Liquid flow regimes in mining industry using Gamma Radiation, In: INTERNATIONAL NUCLEAR ATLANTIC CONFERENCE, 2013, Recife, PE, Brazil.

WILlian, R.G, GESH, C.J., PAGH, R.T., Compendium of Material Composition Data for Radiation Transport Modeling, NM: Los Alamos National Laboratory, Los Alamos, USA, 2006. 